\title{
Nocebo effect in randomized clinical trials of antidepressants in children and adolescents: systematic review and meta-analysis
}

\author{
Johanna Carolina Rojas-Mirquez ${ }^{1,2}$, Milton Jose Max Rodriguez-Zuñiga ${ }^{1}$, \\ Francisco Javier Bonilla-Escobar ${ }^{3,4}$, Herney Andres Garcia-Perdomo ${ }^{4}$, Mike Petkov ${ }^{1}$, Lino Becerra ${ }^{1}$, \\ David Borsook ${ }^{1}$ and Clas Linnman ${ }^{1}$ *
}

\author{
${ }^{1}$ The Pain and Analgesia Imaging Neuroscience (P.A.I.N.) Group, Department of Anesthesiology, Perioperative and Pain Medicine, The Center for Pain and the Brain \\ Boston Children's Hospital, Harvard Medical School, Waltham, MA, USA \\ ${ }^{2}$ Grupo de Epidemiología del Trauma y las Lesiones, Universidad del Valle, Cali, Colombia \\ ${ }^{3}$ Instituto Cisalva, School of Public Health, Universidad del Valle, Cali, Colombia \\ ${ }^{4}$ Cochrane Center, Universidad del Valle, Cali, Colombia
}

\section{Edited by:}

Francesca Cirulli, Istituto Superiore di

Sanità, Italy

Reviewed by:

Francesca Cirulli, Istituto Superiore di Sanità, Italy

Michael Deuschle, Central Institute of Mental Health, Germany

*Correspondence:

Clas Linnman, The Pain and Analgesia Imaging Neuroscience (P.A.I.N.)

Group, Department of

Anesthesiology, Perioperative and

Pain Medicine, The Center for Pain

and the Brain, Boston Children's

Hospital, Harvard Medical School, 9

Hope Avenue, Waltham, MA 02453,

USA

e-mail: clas.linnman@

childrens.harvard.edu
Objective: To compare the incidence of adverse events between active and placebo arms of randomized clinical trials in depressive children and adolescents (C\&A) with antidepressant treatments, in order to look for similarities in both groups that allow to establish a possible nocebo effect.

Methods: Systematic search strategy (January 1974-March 2013) in electronic databases, conference abstracts, and reference list of systematic reviews and included studies to identify parallel randomized placebo-controlled trials of antidepressants in C\&A $(<19$ years $)$ with major depressive disorder, and one or more interventions of any orally administered antidepressant. The pooled adverse events were calculated based on a fixed-effect model and statistical analysis involved the risk ratio (RR) of adverse events, with $95 \%$ confidence intervals $(95 \% \mathrm{Cl})$.

Results: Sixteen studies were included in the review, of which seven studies with a sample of 1911 patients had data to include in the meta-analysis. There was similar risk for the incidence of adverse events between non-active and active group (global RR 1.04, 95\% Cl: 0.97-1.11).

Conclusion: Depressive C\&A allocated to placebo or active group had similar risk to develop adverse events. These similarities in both groups are attributed to the nocebo effect. It is of note that defining "nocebo" effects is challenging in clinical populations because adverse effects may be attributed to the intervention or may be manifestation of the disease itself. The inclusion of a no-treatment arm may be warranted. Nocebo effects are likely when adverse events of placebo mimic the adverse events of active treatment, as was the case here.

Keywords: nocebo, children, adolescents, antidepressants, meta-analysis

\section{INTRODUCTION}

The use of antidepressants for children and adolescents (C\&A) is still a matter of debate due to questionable efficacy and risk of adverse events. The efficacy of these medications appears to be influenced by patient such as function indication, age, chronicity, and study characteristics (Bridge et al., 2007). Negative effects of placebo - nocebo effects (NE) - occur in $25 \%$ of patients (Hauser et al., 2012a). NE can be induced by negative expectation, suggestion, and previous experiences, and are influenced by psychological characteristics as well as therapy situation and context (Wells and Kaptchuk, 2012; Ciaramella et al., 2013), which can influence the expectations of patient, the clinician, and other involved parties.

Systematic reviews have proved the efficacy of antidepressants compared to placebo in adults with major depressive disorder
(MDD) (Undurraga and Baldessarini, 2012). The adverse effect profiles between different therapy groups such as selective serotonin receptor inhibitors (SSRIs) and tricycle antidepressants (TCAs) are prone to systematic expectation influences in both patients and investigators (Gracely et al., 1985; Mora et al., 2011). In C\&A, the effectiveness of antidepressant drugs is a controversial topic (Hazell, 2009) since there is an important incidence of $\mathrm{AE}$ and suicide-related events using SSRIs. Hence, these drugs have received a "black-box" warning by the Food and Drug Administration and the Medicines and Healthcare products Regulatory Agency cautions physicians on their use in C\&A (Hetrick et al., 2012).

Defining "nocebo" effects is challenging in clinical populations. An adverse effect (such as dry mouth, loose stool, frequent 
urinations, or insomnia) may be a "nocebo" or it may be somatic manifestations of the disease itself. Additionally, factors related with NE have been identified in the pediatric population that may lead to confusion, such as divergent behaviors of the disease and parental/cultural influence (Fernandes et al., 2008). The nocebo profile seems to parallel drug side effects in adults (Brambilla et al., 2005). In the context of a randomized clinical trial, in order to assess a true placebo or nocebo effect, the non-active drug should ideally be compared to a no-treatment group. True placebo response would be symptom improvements in the non-active treatment arm that go above and beyond spontaneous remission in the no-treatment group. Likewise, true nocebo responses are adverse effects that go above and beyond symptoms in the no-treatment group. An unfortunate methodological fact is that very few RCT's include such a no-treatment group. Thus, we call adverse events in non-active arms "nocebo-like effects," with the caveat that such effects may in part be spontaneous symptoms and manifestations of disease rather than true NE. This metaanalysis aims to compare the incidence of adverse events between active and placebo arms of randomized clinical trials in depressive C\&A with SSRI, TCA, and SSNRI treatments, in order to look for similarities in adverse effect profiles in active and placebo arms.

\section{MATERIALS AND METHODS}

We conducted a systematic review and meta-analysis of antidepressant RCTs in C\&A with MDD to describe and compare the $\mathrm{AE}$ in placebo and treatment arms. This study was conducted according to the recommendations of the Cochrane Collaboration (Higgins and Green, 2011a) and the PRISMA Statement (Moher et al., 2009), PROSPERO code CRD42013004638 (Rojas-Mirquez et al., 2013).

\section{ELIGIBILITY CRITERIA \\ Studies}

We included parallel, placebo-controlled RCTs of antidepressants in depressed C\&A conducted between 1/1/1974 and 3/31/2013. Other types of RCTs and those that assessed other condition simultaneously were excluded. No language restrictions were imposed.

\section{Participants}

Female and male children (6-12 years) (National Center for Biotechnology Information, 2013a) and/or adolescents (1318 years) (National Center for Biotechnology Information, 2013b) with MDD diagnosed with specific criteria. There were no preferences in any other demographic characteristic of participants.

\section{Interventions}

RCTs that compared placebo with one or more orally administered antidepressant drugs. There was no restriction of dosage, frequency, or duration of the treatment.

\section{Outcomes}

The primary outcome measure was the incidence of $\mathrm{AE}$ in placebo and treatment groups looking for similarities in both groups that allow to establish a possible NE. The secondary outcome was the efficacy of antidepressant treatment for C\&A with MDD.

\section{INFORMATION SOURCES AND SEARCH STRATEGY}

We designed a search strategy for RCTs published in PubMed, CENTRAL, EMBASE, and BIREME. The search strategy was specific for each database and includes a combination of the medical subject headings and free text terms (see Table 1). Clinicaltrials.gov for RCTs and biosis.org for conference abstracts were used to find additional studies, as well as reference lists of selected articles, reviews, and previous meta-analyses.

\section{STUDY SELECTION}

Two investigators (Johanna Carolina Rojas-Mirquez, Milton Jose Max Rodriguez-Zuñiga) independently screened the titles and abstracts to determine the potential usefulness of the articles. Eligibility criteria were applied to the full text articles during the final selection. We resolved disagreements by consensus and by a third reviewer (Herney Andres Garcia-Perdomo).

\section{DATA COLLECTION PROCESS}

All data were collected independently by two authors using a standardized data extraction sheet in Epi-Info ${ }^{\mathrm{TM}} 7.0$ software (Centers for Disease Control and Prevention, CDC, Atlanta, GA, USA). An independent reviewer (Francisco Javier Bonilla-Escobar) confirmed all data entries and checked at least twice for completeness and accuracy.

\section{DATA ITEMS}

We extracted variables related with characteristics of the article, study design, patient's data, and AE. All types of adverse events were included since authors of included clinical trials did not provide detail on the nature of adverse event reported. When data were not available, this was noted.

\section{RISK OF BIAS IN INDIVIDUAL STUDIES AND ACROSS THEM}

The Cochrane Collaboration risk of bias tool (Higgins et al., 2011; Sterne and Moher, 2011) was used independently by two researchers (Johanna Carolina Rojas-Mirquez, Milton Jose Max Rodriguez-Zuñiga). Disagreements were solved by consensus. A "Risk of bias table" and a risk of bias summary were edited using Review Manager Software Version 5.1 ${ }^{\circledR}$ (RevMan) to illustrate the judgments for each study.

\section{QUALITY ASSESSMENT OF AE}

A Cochrane tool to assess quality and report of AE was used to evaluate the methodology that researchers used as well as the quality of the reports for published studies (Higgins and Green, 2011b).

\section{SYNTHESIS OF RESULTS}

The risk ratio (RR) was the effect measured of the primary outcome, with $95 \%$ confidence intervals (95\% CI). The efficacy of antidepressant treatment was defined as the standardized mean difference (SMD) between baseline and post-treatment values on depression scales. AE were only evaluated over the course of the intervention.

Included trials were characterized with descriptive statistics and median with 25th-75th percentiles (p25-p75) such as central tendency and dispersion measures. Quantitative data were analyzed with non-parametric tests, due to their non-normal distribution 


\begin{tabular}{|c|c|c|c|c|c|c|c|c|c|c|c|c|c|c|c|c|c|c|}
\hline \multirow[t]{2}{*}{ Author } & \multirow[t]{2}{*}{$\begin{array}{l}\text { Therapy } \\
\text { group }\end{array}$} & \multirow[t]{2}{*}{$\begin{array}{l}\text { FDA } \\
\text { appr- } \\
\text { oval }\end{array}$} & \multirow[t]{2}{*}{$\begin{array}{l}\text { Therapy } \\
\text { duration } \\
\text { (days) }\end{array}$} & \multirow[t]{2}{*}{$\begin{array}{l}\text { Popul- } \\
\text { ation }\end{array}$} & \multirow[t]{2}{*}{$\begin{array}{l}\text { Sample } \\
\text { size }\end{array}$} & \multirow[t]{2}{*}{$\begin{array}{l}\text { Patients } \\
\text { on } \\
\text { placebo } \\
(n)\end{array}$} & \multirow{2}{*}{$\begin{array}{l}\text { Patients } \\
\text { on } \\
\text { therapy } \\
\text { group } \\
\text { (n) }\end{array}$} & \multirow[t]{2}{*}{$\begin{array}{l}\text { Drop- } \\
\text { outs } \\
(n)\end{array}$} & \multirow[t]{2}{*}{$\begin{array}{l}\text { Efficacy } \\
\text { outcome } \\
\text { measure } \\
\text { tool }\end{array}$} & \multicolumn{2}{|c|}{$\begin{array}{l}\text { Baseline } \\
\text { measure } \\
\text { (mean) }\end{array}$} & \multicolumn{2}{|c|}{$\begin{array}{l}\text { Postreatment } \\
\text { (mean) }\end{array}$} & \multicolumn{2}{|c|}{$\Delta$ Efficacy } & \multirow[t]{2}{*}{$\begin{array}{l}\text { Assess- } \\
\text { ment } \\
\text { strategy } \\
\text { for AEs }\end{array}$} & \multirow[t]{2}{*}{$\begin{array}{l}\text { AEs } \\
\text { placebo } \\
(n)\end{array}$} & \multirow[t]{2}{*}{$\begin{array}{l}\text { AEs } \\
\text { therapy } \\
\text { group } \\
(n)\end{array}$} \\
\hline & & & & & & & & & & $\begin{array}{l}\text { Plac- } \\
\text { ebo }\end{array}$ & $\begin{array}{l}\text { The- } \\
\text { rapy }\end{array}$ & $\begin{array}{l}\text { Plac- } \\
\text { ebo }\end{array}$ & $\begin{array}{l}\text { The- } \\
\text { rapy }\end{array}$ & $\begin{array}{l}\text { Plac- } \\
\text { ebo }\end{array}$ & $\begin{array}{l}\text { The- } \\
\text { rapy }\end{array}$ & & & \\
\hline Berard et al. (2006) & Paroxetine & No & 84 & $\begin{array}{l}\text { Adole- } \\
\text { scents }\end{array}$ & 286 & 99 & 187 & 90 & MADRS & 25.9 & 25.9 & 13.1 & 12.3 & 12.8 & 13.6 & Structured & 56 & 119 \\
\hline Kye et al. (1996) & Amitriptyline & No & 56 & $\begin{array}{l}\text { Adole- } \\
\text { scents }\end{array}$ & 31 & 13 & 18 & 9 & HAM-D & 13.2 & 12 & 8.8 & 8 & 4.4 & 4 & Structured & NR & $N R$ \\
\hline Geller et al. (1992) & Nortriptyline & No & 56 & Children & 60 & 29 & 31 & 10 & CDRS-R & 49.6 & 49.9 & 32 & 32.9 & 17.6 & 17 & Structured & NR & NR \\
\hline Keller et al. (2001) & $\begin{array}{l}\text { (1): Paroxetine } \\
\text { (2): Imipramine }\end{array}$ & No & 56 & $\begin{array}{l}\text { Adole- } \\
\text { scents }\end{array}$ & 275 & 87 & $\begin{array}{l}\text { (1): } 93 \\
\text { (2): } 95\end{array}$ & 86 & HAM-D & 18.97 & $\begin{array}{l}\text { (1): } 18.98 \\
\text { (2): } 18.11\end{array}$ & 9.88 & $\begin{array}{l}\text { (1): } 8.24 \\
\text { (2): } 9.2\end{array}$ & 9.09 & $\begin{array}{l}\text { (1): } 10.74 \\
\text { (2): } 8.91\end{array}$ & Observations & NR & NR \\
\hline Wagner et al. (2004) & Citalopram & No & 56 & Both & 178 & 85 & 93 & 36 & CDRS-R & 57.8 & 58.8 & 41.8 & 37.8 & & & Combination & NR & NR \\
\hline $\begin{array}{l}\text { GlaxoSmithKline } \\
\text { (2011) }\end{array}$ & Paroxetine & No & 56 & Both & 56 & 27 & 29 & 7 & CDRS-R & NR & NR & -11.9 & -16.5 & 11.9 & 16.5 & Structured & 9 & 9 \\
\hline Emslie et al. (2009) & Escitalopram & No & 56 & $\begin{array}{l}\text { Adole- } \\
\text { scents }\end{array}$ & 316 & 158 & 158 & 53 & CDRS-R & 56 & 57.6 & 37.2 & 35.5 & 18.8 & 22.1 & Combination & 118 & 121 \\
\hline Simeon et al. (1990) & Paroxetine & No & 49 & $\begin{array}{l}\text { Adole- } \\
\text { scents }\end{array}$ & 40 & 20 & 20 & 10 & HAM-D & NR & NR & NR & $N R$ & & & Not stated & NR & $N R$ \\
\hline $\begin{array}{l}\text { Almeida-Montes } \\
\text { (2005) }\end{array}$ & Fluoxetine & Yes & 30 & Both & 23 & 11 & 12 & 7 & DSR-S & NR & NR & NR & $N R$ & & & Structured & NR & $N R$ \\
\hline Wagner et al. (2006) & Escitalopram & No & 56 & Both & 268 & 136 & 132 & 51 & CDRS-R & 56.6 & 54.5 & 36.4 & 32.6 & 20.2 & & Combination & 90 & 90 \\
\hline $\begin{array}{l}\text { Eli Lilly and } \\
\text { Company (2013a) }\end{array}$ & $\begin{array}{l}\text { (1): Duloxetine } \\
\text { (2): Fluoxetine }\end{array}$ & No & 70 & Both & 337 & 103 & $\begin{array}{l}\text { (1): } 117 \\
\text { (2): } 117\end{array}$ & 72 & CDRS-R & 60.2 & $\begin{array}{l}\text { (1): } 59.2 \\
\text { (2): } 58.8\end{array}$ & 35.9 & $\begin{array}{l}\text { (1): } 34.9 \\
\text { (2): } 35.1\end{array}$ & 24.3 & $\begin{array}{l}\text { (1): } 24.3 \\
\text { (2): } 23.7\end{array}$ & Structured & 68 & $\begin{array}{l}\text { (1): } 70 \\
\text { (2): } 72\end{array}$ \\
\hline Kutcher et al. (1994) & Desipramine & No & 42 & $\begin{array}{l}\text { Adole- } \\
\text { scents }\end{array}$ & 60 & 30 & 30 & 18 & CDRS-R & 23.77 & 22.63 & 13.42 & 12.68 & & & Structured & NR & NR \\
\hline Wagner et al. (2003) & Sertraline & No & 70 & Both & 376 & 187 & 189 & 77 & CDRS-R & 64.6 & 64.3 & 38.77 & 34.06 & & & Combination & NR & NR \\
\hline Emslie et al. (2002) & Fluoxetine & yes & 56 & Both & 219 & 110 & 109 & 61 & CDRS-R & 55.1 & 57.1 & 40.2 & 35.1 & 14.9 & 22 & Combination & NR & NR \\
\hline $\begin{array}{l}\text { Eli Lilly and } \\
\text { Company (2013b) }\end{array}$ & $\begin{array}{l}\text { (1): Duloxetine } \\
60 \mathrm{mg}\end{array}$ & No & 70 & Both & 463 & 122 & (1): 108 & 138 & CDRS-R & 58.2 & (1): 59.3 & 36.6 & (1): 35.4 & 21.6 & (1): 23.9 & Structured & 71 & (1): 76 \\
\hline & $\begin{array}{l}\text { (2): Duloxetine } \\
30 \mathrm{mg}\end{array}$ & & & & & & (2): 116 & & & & (2): 11 & & (2): NR & & (2): NR & & & (2): 66 \\
\hline & $\begin{array}{l}\text { (3): Fluoxetine } \\
30 \mathrm{mg}\end{array}$ & & & & & & (3): 117 & & & & (3): 57.9 & & (3): NR & & (3): NR & & & (3): 69 \\
\hline Emslie et al. (2006) & Paroxetine & No & 56 & Both & 206 & 102 & 104 & 54 & CDRS-R & 62.6 & 60.7 & 39.2 & 38.1 & 23.4 & 22.6 & $\begin{array}{l}\text { Spontaneous } \\
\text { reports }\end{array}$ & 62 & 71 \\
\hline
\end{tabular}

(1), Arm 1; (2), Arm 2; (3), Arm 3.

FDA, Food and Drug Administration; $n$, number of patients; $\Delta$, difference between baseline and post-treatment values on depression scales; AEs, adverse events; MADRS, Montgomery-Asberg Depression Rating Scale; HAM-D, Hamilton Depression Rating Scale; CDRS-R, Children's Depression Rating Scale-Revised; DSR-S, Depression Self-Rating Scale; NR, no report; RCTS, randomized clinical trials. 
assessed by Shapiro-Wilk method. The confidence level was 95\%, and these analyses were performed on Stata13 ${ }^{\circledR}$ (College Station, TX, USA: StataCorp LP).

Heterogeneity between trials was assessed through the $I^{2}$ statistic, which indicates the percentage of variation in the effect size estimate attributable to heterogeneity rather than sampling error ( $I^{2}$ value greater or equal to $50 \%$ represents heterogeneity) (Higgins et al., 2003). The pooled AE and efficacy on both groups were calculated based on a fixed and random effect model, respectively, taking into account the heterogeneity of the studies. If studies show heterogeneity, results are based on a random effect model, and if studies are homogeneous, their results are based on a fixed-effect model (Bollen and Brand, 2010). Results are reported as forest plots showing the effect size of all the included studies with $95 \%$ CI.

\section{Subgroup analysis}

They were performed on the basis of age category (C\&A) and drug category (SSRIs, NRIs, and TCAs) through RevMan ${ }^{\circledR}$.

\section{Sensitivity analysis}

The relative RR was used for all primary analyses, and the MantelHaenszel random effects model was used for sensitivity analysis (Der-Simonian and Laird, 1986). We undertook the sensitivity analysis based on the exclusion of each one of the trials, as well as the unpublished and the smallest trials.

\section{MISSING DATA}

All data were used in the systematic review. Corresponding authors were contacted in the cases of missing data. The pooled available data were used for the meta-analysis.

\section{RESULTS \\ STUDY SELECTION}

We identified 1018 studies. The final sample size meeting all inclusion criteria consisted of 16 studies performed in C\&A with MDD, whereof seven studies met the criteria for quantitative analysis. Selection process and characteristics of excluded studies are detailed in Figure 1.

\section{STUDY CHARACTERISTICS}

We analyzed 16 studies with a total of 3194 patients. Of those, 1319 were randomized to non-active and 1875 to an active group. The study sample sizes ranged from 23 to 463 patients. Thirteen were published in journals, while the rest were studies available on a clinical trial register for unpublished data (see Table 1).

In the age group analysis, nine out of 16 studies were carried out in both age groups (C\&A), six trials were performed just in adolescents and one trial included only children (Geller et al., 1992). 313 children and 678 adolescents were included to non-active and 319 and 869 to an active drug, with no difference in proportions of children allocated to non-active or to an active arm by pharmacologic group $(p=0.17)$; however, there were significantly more adolescents in the SSNRI trials than in TCA trials $(p=0.002)$. The median age for all included participants was 13 (10-16), and it was similar for participants in the non-active and active group $(p=0.67)$.
All studies included both genders. In the 14 trials that reported the participants' gender (3389 patients), 54\% were female. Of those, $40 \%$ were allocated in non-active and $60 \%$ in an active group $(p=0.68)$. There was a significant difference between the proportion of males and females by pharmacologic group, with a higher proportion of males in the TCA studies and a majority of females in SSRI and SNRI studies $(p=0.0074)$.

Thirteen out of 16 trials assessed a SSRI in at least one of its arms, two a SNRI and four a TCA. Not including non-active arms, 13 studies had one active intervention arm, two trials had two active intervention arms (Keller et al., 2001; Eli Lilly and Company, 2013a), and one trial had three arms (Eli Lilly and Company, 2013b). There were 10 different drugs used in the active arms, with five paroxetine trials (Simeon et al., 1990; Keller et al., 2001; Berard et al., 2006; Emslie et al., 2006; GlaxoSmithKline, 2011), four fluoxetine (Emslie et al., 2002; Almeida-Montes, 2005; Eli Lilly and Company, 2013a,b), three duloxetine (Eli Lilly and Company, 2013a,b), two escitalopram trials (Wagner et al., 2006; Emslie et al., 2009), and single studies of imipramine (Keller et al., 2001), amitriptyline (Kye et al., 1996), nortriptyline (Geller et al., 1992), citalopram (Wagner et al., 2004), desipramine (Kutcher et al., 1994), and sertraline (Wagner et al., 2003).

A pharmaceutical company sponsored 13 out of the 16 trials, one was sponsored by the National Institute of Mental Health (Geller et al., 1992), one by the Nordic Merrell Dow Research and the Ontario Mental Health Foundation (Kutcher et al., 1994), and one did not provide information about the sponsor (Simeon et al., 1990).

The median intervention period had 56 (56-63) days of exposure to a drug, with 56 (30-84) days to SSRI, 70 (70-70) to SNRI, and $56(42-56)$ days to TCAs, without significant differences $(p=0.11)$.

All trials used more than one tool for depression diagnosis with 12 out of 16 trials used the DSM-IV (Diagnostic and Statistical Manual of Mental Disorders, Fourth Edition), 10 using the Children Depression Scales-Revised (CDS-R), and 8 using the Kiddie-Schedule for affective disorders and schizophrenia for school-age children (K-SADS-P). All the trials assessed the efficacy of the drug as the primary outcome. The most frequent primary outcome measure tool used was CDRS-R in 11 trials, while three used Hamilton Depression Rating Scale, one used the Montgomery and Asberg Depression Rating Scale (MADRS) (Berard et al., 2006), and the Depression Self-Rating Scale (DSR-S), respectively (Almeida-Montes, 2005).

The total number of dropouts was 779 , whereof $63 \%$ were allocated in the active group. The total rate of discontinuation was $22 \%$ with median discontinuation rate for placebo and active groups of 20\% (11-38) and 25\% (14-43), respectively. There were no statistically significant difference $(p=0.06)$, nor by pharmacologic group $(p=0.93)$.

\section{RISK OF BIAS WITHIN AND ACROSS STUDIES}

The risk of bias summary was performed to show how each study was assessed for each domain (see Figure S1 in Supplementary Material). Around $90 \%$ of the trials had high risk of attrition bias, related to withdrawals and dropouts. All trials had an unclear risk of selection bias, associated to the lack of information about the 


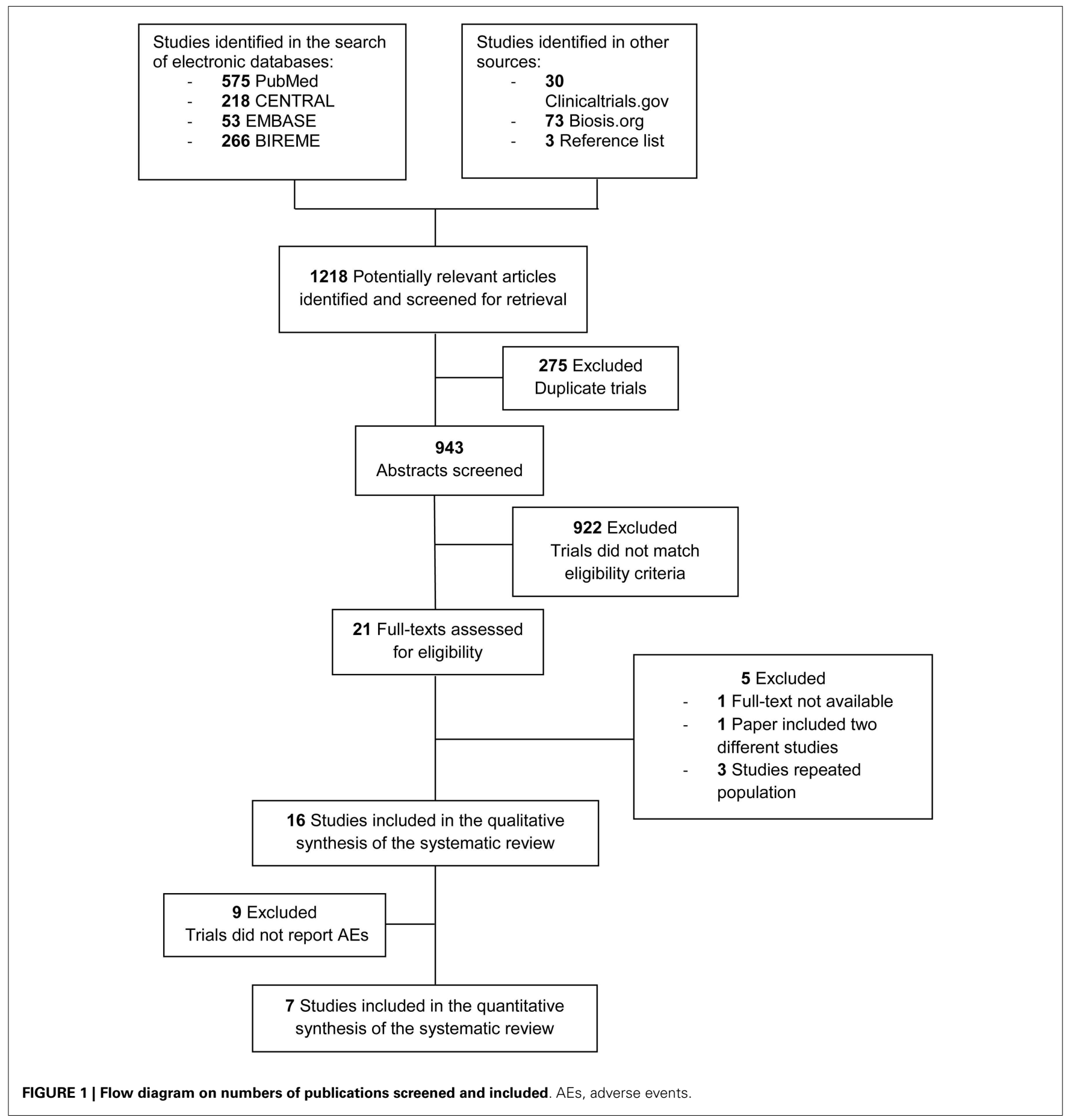

allocation concealment process. Nearly $85 \%$ of trials had low risk of other bias, considering the comparable condition of the arms in their baseline characteristics. In all, $75 \%$ of studies were unclear about the masking method, although all trials were defined as double blinded (Figure 2).

\section{QUALITY ASSESSMENT ON CONDUCT AND REPORT OF AE}

Cochrane's tool was applied to 13 published studies, which provided the necessary information in order to do a judgment regarding the conduct and report of adverse events. The most frequent $\mathrm{AE}$ evaluation strategy was structured assessment (eight out of 16), using weekly scales, checklist, and questionnaires. The combination of assessment methods (five out of 16) consisted in spontaneous reports, physical examination of patients in each visit, and observation by investigators, while two trials used either spontaneous report of symptoms by the patient or observation and physical examination by the care professional in charge. One trial did not provide information on its assessment strategy for 
Random sequence generation (selection bias)

Allocation concealment (selection bias)

Blinding of participants and personnel (performance bias) Blinding of outcome assessment (detection bias)

Incomplete outcome data (attrition bias)

Selective reporting (reporting bias)

Other bias

Low risk of bias

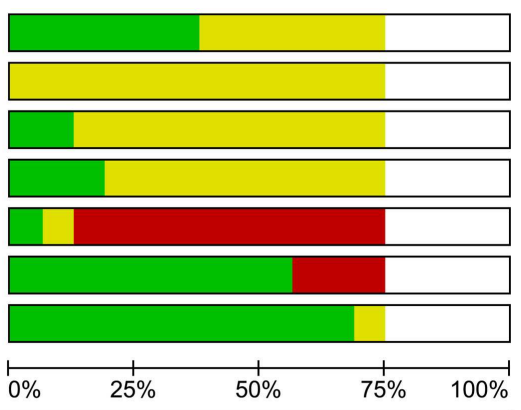

High risk of bias

FIGURE 2 | Risk of bias across all included studies

AE (Simeon et al., 1990). Of the seven studies included in the quantitative analysis, four used a structured method, either weekly $\mathrm{AE}$ monitoring or systematic assessment of AE, two used a combination that included spontaneous report and observation by investigators and one included study used the spontaneous report by patients (see Table S1 in Supplementary Material) (Emslie et al., 2006).

\section{RESULTS OF INDIVIDUAL STUDIES AND SYNTHESIS OF RESULTS}

The most frequents AE were headache (RR 1.22, 95\% CI 0.871.71), nausea (RR 1.88, 95\% CI 1.44-2.45), dizziness (RR 2.04, 95\% CI 1.41-2.96), abdominal pain (RR 1.18, 95\% CI 0.81-1.72), vomiting (RR 1.58, 95\% CI 1.07-2.34), insomnia (RR 2.16, 95\% CI 1.42-3.27), somnolence (RR 1.51, 95\% CI 0.78-2.92), and decrease appetite (RR 1.58, 95\% CI 0.95-2.61); these are reported according to the rank of frequency of AE in placebo groups. Of the above symptoms, nausea, vomiting, insomnia, and dizziness had more significant risk to be present in patients taking antidepressants, compared to non-active treatment (see Figure S2 in Supplementary Material).

\section{Nocebo effects}

The pooled effect estimate of NE was calculated with seven out of 16 trials that reported the number of patients who presented adverse events for each intervention group (1911 patients, 39\% were in non-active group). The heterogeneity for the adverse effects' RR was low $\left(I^{2}=0 \%\right)$, and there was no increased risk in developing them in patients allocated to an active drug and those allocated to non-active (RR 1.04, 95\% CI 0.97-1.11). All the trials had similar risk to present $\mathrm{AE}$ in patients taking an active drug or taking placebo (Figure 3A). Table S2 in Supplementary Material shows the five most frequent $\mathrm{AE}$ for each one of the pharmacological group of antidepressants, and those that presented higher risk of development in non-active groups. Headache and nausea were the symptoms presented more frequently in patients allocated in non-active groups compared with any active treatment group, with proportions of 14 and 7\%, respectively.

\section{SSRIs trials}

Following headache and nausea, nasopharyngitis, abdominal pain, and vomiting were the most common AE presented by patients of non-active groups (see Table S2 in Supplementary Material). Nasopharyngitis was a NE, with RR 0.94 (95\% CI 0.64-1.39).

\section{SNRIs trials}

Following headache and nausea, abdominal pain upper, dizziness, and somnolence were the most common AE presented by patients of non-active groups (see Table S2 in Supplementary Material). Abdominal pain was a NE with a RR 0.89 (95\% CI 0.54-1.44).

\section{TCAs trials}

Following headache and nausea, dizziness, dry mouth, and respiratory disorder were the most common $\mathrm{AE}$ presented by patients of non-active groups (see Table S2 in Supplementary Material). Headache and respiratory disorder were NEs, with RR 0.96 (95\% CI $0.66-1.39$ ) and 0.58 (95\% CI 0.23-1.45), respectively. Of note, dizziness and dry mouth were significantly more common in the active treatment groups.

\section{Efficacy analysis}

Ten out of 16 trials reported measures baseline and post-treatment for each intervention group. In all, 1123 patients in the active group and 828 in non-active group were included to calculate the pooled estimate of antidepressants efficacy. The heterogeneity for efficacy analysis was high $\left(I^{2}=96 \%\right)$, and there was a mild, but statistically significant reduction in the depression score scales in patients taking an antidepressant drug as compared to placebo, with the estimates in the same direction (SMD $-1.79,95 \%$ CI -2.92 to -0.66 ) (Figure 4A).

\section{ADDITIONAL ANALYSIS \\ Subgroup analysis}

In the analysis of pharmacologic drug group and risk of AE, there were no significant differences seen among a SSRI drug (RR 1.04, 95\% CI 0.97-1.12) or a SNRI drug (RR 1.01, 95\% CI 0.88-1.15) in comparison to non-active drug (Figure 3B). For patients taking a TCA and SNRI, there was no significant change in the depression severity scales compared to placebo (SMD TA 0.18, 95\% CI -0.09 to -0.45 ; SMD SNRI $-1.24,95 \%$ CI -3.49 to -1.01 ). On the other hand, there was a significant reduction in the depression severity scales in patients taking a SSRI drug (SMD - 2.11, 95\% CI -3.25 to -0.96 ) (Figure 4B). 


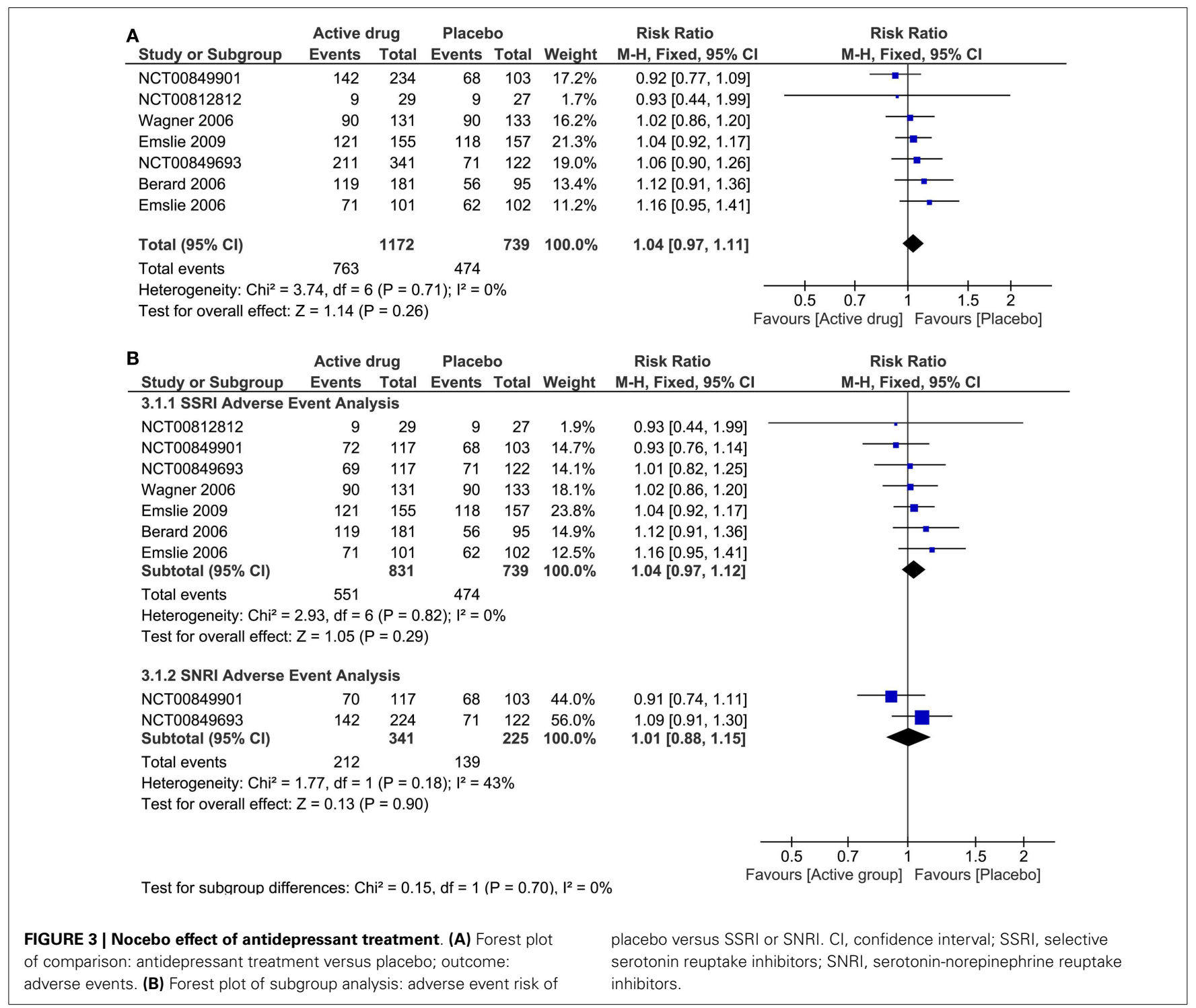

The subgroup analysis by age was only done for efficacy. We included four trials that were conducted solely in adolescents, and one trial that involved only children. There was no difference in the decrease of the depression scales in children or in adolescents who took an active drug in comparison to non-active, although adolescents showed a better improvement (SMD adolescents -1.47 , 95\% CI -3.01 to -0.07 ; SMD children $0.06,95 \% \mathrm{CI}-5.77$ to -6.97) (Figure 4C).

\section{Sensitivity analysis}

For sensitivity analysis, we stepwise removed each trial in the $\mathrm{AE}$ analysis; neither of them exerted a significant change in the recalculated overall $\mathrm{RR}$.

\section{DISCUSSION}

\section{NOCEBO EFFECT}

Despite higher representation in placebo, both patients allocated to non-active and experimental groups had similar risk to develop
AE. This has already been reported by other authors in pain-related trials (Amanzio et al., 2009; Hauser et al., 2012b; Mitsikostas et al., 2012) and clinical trials of depression in adults (Rief et al., 2009; Hegerl et al., 2010).

It should be noted that no RCTs included a no-treatment arm. As such, it is not possible to define whether adverse events are true NE, or manifestations of the disease itself. However, there are several indications that the reported adverse events are indeed of "nocebo" type. In previous systematic reviews on TCA trials, it has been shown that the most frequent nocebo symptoms were headache, nausea, dizziness, dry mouth palpitations, and tremor (Hazell and Mirzaie, 2013). In the current analysis of multiple types of antidepressants, we found the two most frequent instances of NE to be headache and nausea, where only nausea showed a significantly increased risk in placebo arms. The placebo group of TCAs trials was more likely to present dizziness and dry mouth, SNRIs upper abdominal pain and dizziness, and SSRIs nasopharyngitis and abdominal pain. The placebo groups in TCAs 


\begin{tabular}{|c|c|c|c|c|c|c|c|}
\hline \multirow[b]{2}{*}{ Study or Subgroup } & \multicolumn{3}{|c|}{ Active drug } & \multicolumn{3}{|c|}{ Placebo } & \multirow[b]{2}{*}{ Weight } \\
\hline & Mean & SD & Total & Mean & SD & Total & \\
\hline Emslie 2002 & -22 & 16.74 & 109 & -14.9 & 17.9294 & 110 & $4.4 \%$ \\
\hline NCT00812812 & -16.5 & 2.45 & 29 & -11.9 & 2.54 & 27 & $13.6 \%$ \\
\hline Emslie 2009 & -22.1 & 1.3862 & 154 & -18.9 & 1.4309 & 157 & $16.5 \%$ \\
\hline NCT00849693 & -23.9 & 10.9468 & 105 & -21.6 & 9.4354 & 117 & $8.5 \%$ \\
\hline Berard 2006 & -13.6 & 0.9579 & 177 & -12.8 & 1.2305 & 91 & $16.5 \%$ \\
\hline Keller 2001 & -9.8051 & 1.2941 & 184 & -9.09 & 0.9393 & 87 & $16.5 \%$ \\
\hline NCT00849901 & -24 & 10.5298 & 226 & -24.3 & 11.722 & 103 & $8.7 \%$ \\
\hline Kye 1996 & -4 & 6.6528 & 12 & -4.4 & 6.0874 & 10 & $3.5 \%$ \\
\hline Geller 1992 & -17 & 12.1489 & 26 & -17.6 & 10.8258 & 24 & $2.6 \%$ \\
\hline Emslie 2006 & -22.6 & 9.4841 & 101 & -23.4 & 9.1017 & 102 & $9.0 \%$ \\
\hline Total $(95 \% \mathrm{Cl})$ & & & 1123 & & & 828 & $100.0 \%$ \\
\hline \multicolumn{8}{|c|}{ Heterogeneity: $\mathrm{Tau}^{2}=1.99 ; \mathrm{Chi}^{2}=201.10, \mathrm{df}=9(\mathrm{P}<0.00001) ; \mathrm{I}^{2}=96 \%$} \\
\hline
\end{tabular}

Mean Difference Mean Difference

IV, Random, $95 \% \mathrm{Cl}$

$-7.10[-11.69,-2.51]$

$-4.60[-5.91,-3.29]$

$-3.20[-3.51,-2.89]$

$-2.30[-5.00,0.40]$

$-0.80[-1.09,-0.51]$

$-0.72[-0.99,-0.44]$

$0.30[-2.35,2.95]$

$0.40[-4.93,5.73]$

$0.60[-5.77,6.97]$

$0.80[-1.76,3.36]$

$-1.79[-2.92,-0.66]$

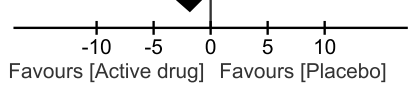

Favours [Active drug] Favours [Placebo]

B

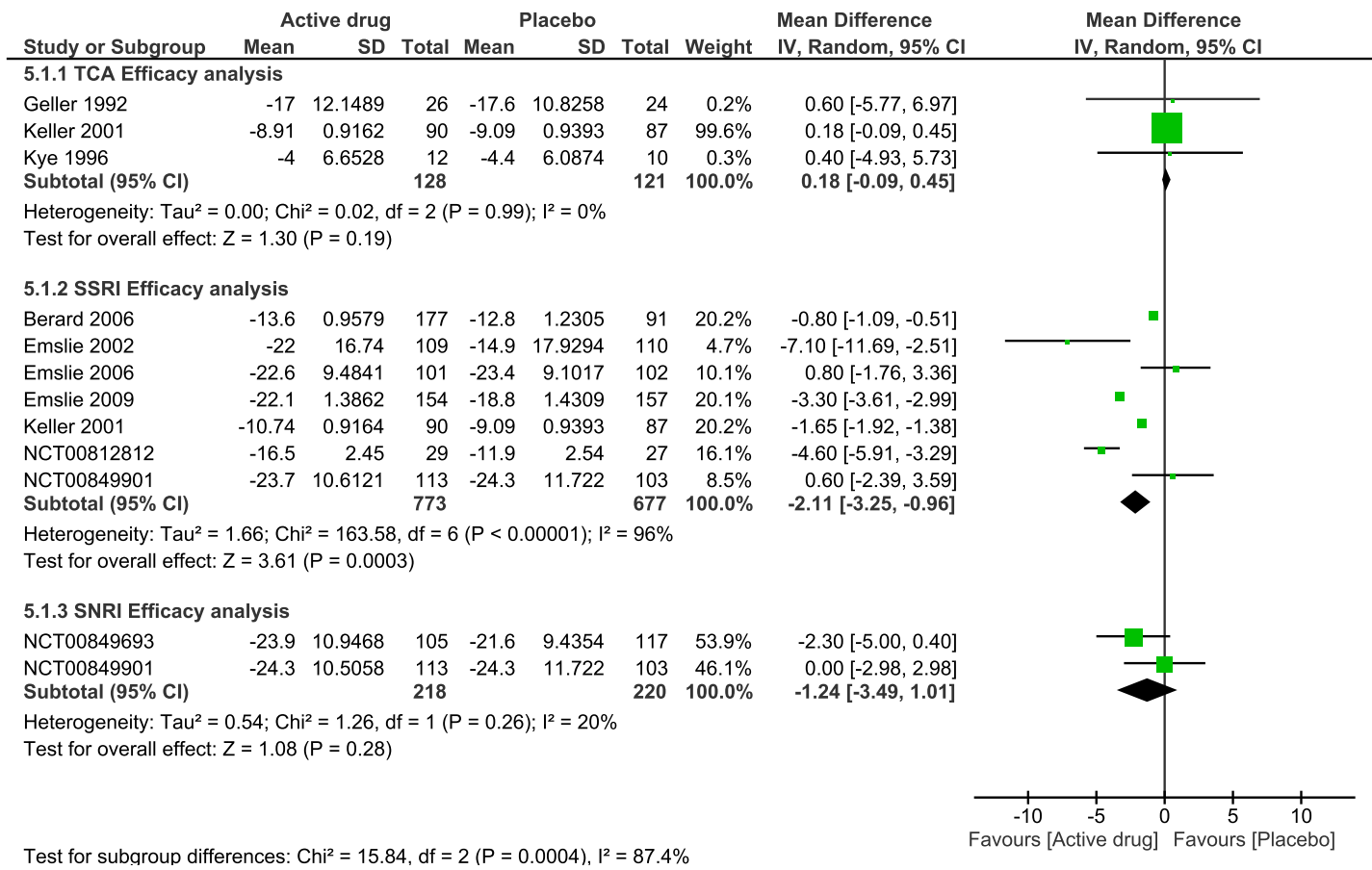

Test for subgroup differences: $\mathrm{Chi}^{2}=15.84, \mathrm{df}=2(\mathrm{P}=0.0004), \mathrm{I}^{2}=87.4 \%$

C

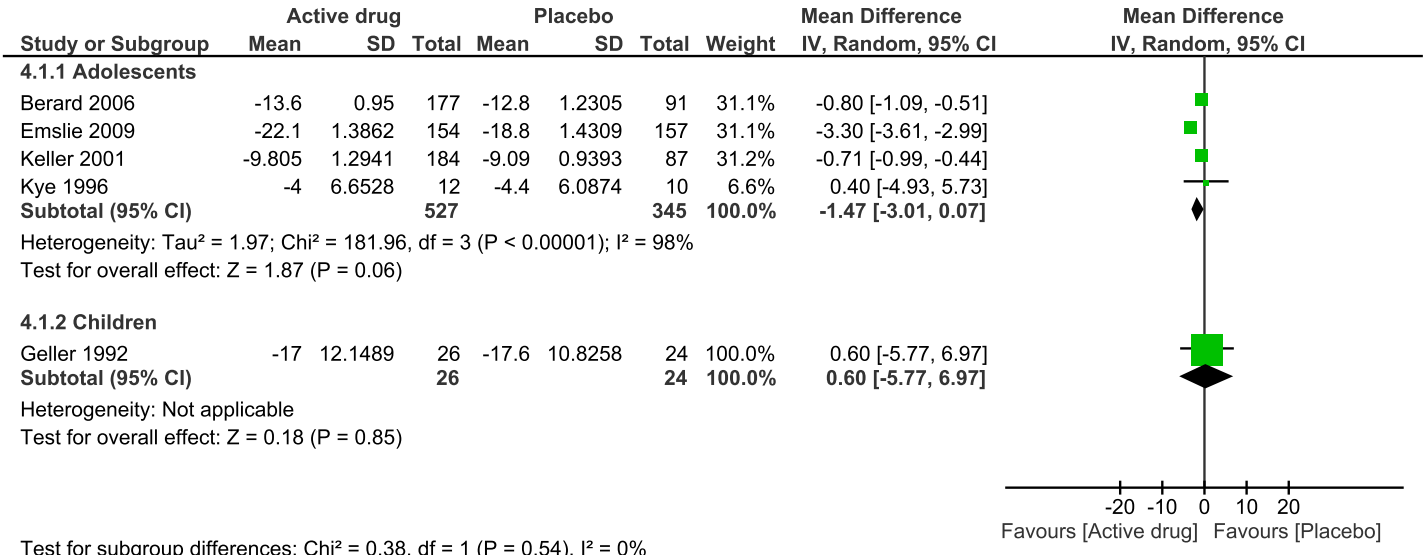

FIGURE 4 | Efficacy of antidepressant treatment. (A) Forest plot of comparison: antidepressant versus placebo, outcome: efficacy. (B) Forest plot of subgroup analysis: efficacy by pharmacologic group of antidepressant versus placebo, and (C) Forest plot of subgroup analysis: efficacy by age group in antidepressant versus placebo. SD, standard difference; $\mathrm{Cl}$, confidence interval; TCA, tricyclic antidepressants; SSRI, selective serotonin reuptake inhibitors; SNRI, serotonin-norepinephrine reuptake inhibitors. 
trials had the highest rate of NE, with nearly $33 \%$ of patients having stronger sedating and cholinergic profile, while placebo groups in the SSRI trials had the lowest rates. This is in accordance with the concept that the nocebo effect profile reflects those effects of active group (Gracely et al., 1985; Amanzio et al., 2009; Mitsikostas et al., 2012). Although our major findings about nocebo effect are similar than those of pain-related trials, it is imperative to highlight that a likely reason of these findings is insufficient descriptions, quality, and reliability AE assessment methods in the included randomized clinical trials.

Headache is commonly seen as a NE that affects compliance and adherence to treatments (Colloca and Miller, 2011; Mitsikostas et al., 2012). It is frequently presented in adolescents with depression (Nardi et al., 2013); however, reports show that healthy adolescents present headaches with prevalence of 11.929.1\% (Ghandour et al., 2004; Bohman et al., 2012). Here, we found an $18 \%$ incidence of headaches among subjects assigned to placebo and $23 \%$ among patients assigned to an active drug, leading to reconsider its status as a real nocebo effect.

Many infection-related AE showed (non-significantly) higher frequency in the non-active group. This phenomenon might be explained by random chance or be related to the association between depression and altered immune function (Jones and Thomsen, 2013). Depression-induced immune system alterations, rather than nocebo, is a possible explanation.

Nocebo effect has been widely attributed to three important factors: expectations (Benedetti and Amanzio, 2013; Faasse and Petrie, 2013), suggestions (van Laarhoven et al., 2011), and conditioning (Hauser et al., 2012b; Data-Franco and Berk, 2013). It can be seen by the nocebo influence of clinicians, parents' expectations, or patients sharing their experiences in the waiting room during visits. Moreover, anxiety-related symptoms of depression, somatization, or generalized psychological distress might influence the development of NE (Rogers, 2003). Bavbek et al. (2014) suggest that higher education and the patient history of hypersensitivity to medications increase the risk of nocebo responses. Less experienced physicians also appear to contribute to the nocebo response (Ashraf et al., 2014). Women may have a slightly larger nocebo response than men (Casper et al., 2001), as may homozygous carriers of the Val158 variant of the catechol-O-methyltransferase (COMT) gene (Val158met) (Wendt et al., 2014).

As suggested by Bingel (2014), some possible strategies to reduce NE include (a) optimizing treatment expectations and expectations of adverse effects, (b) a balanced presentations of risks and benefits, (c) teaching coping skills, (d) providing evidencebased information as opposed to alarmist web-forums, (e) better drug leaflet information, (f) hidden tapering in of medications, (g) pretreatment with drugs with low adverse effects, (h) video clips with patient examples coping well with adverse effects, (i) authentic and empathic patient-physician communication, ( $j$ ) adequate information regarding disease, diagnoses, treatments, and adverse effects, (k) systematic feedback to patients, (1) pedagogical teaching (such as proactive check-back questions) to prevent negative biases and misunderstandings, and ( $\mathrm{m}$ ) adequately addressing patients' anxieties, concerns, and expectations.

It is important to consider these factors in clinical and research practice in order to control this phenomenon. As the "therapeutic ritual" play an important role for the placebo and nocebo mechanism (Benedetti, 2012), physicians should cultivate positive reinforcement and continuous support to ensure patients' adherence to the procedure and minimize the likelihood of nocebo (Benedetti and Amanzio, 2011).

Some authors have made some recommendations to reduce the nocebo effect in RCT's. For instance, Amanzio (2011) have proposed the use of the natural history group as a "third arm" in pain trials, allowing the comparison of placebo groups with non-treated groups in order to seek for specific nocebo symptoms. Moreover, Cohen (2014) has proposed new approaches in the informed consent of trials that aim to avoid the nocebo influence due the advertisement of potential adverse events. Although these options could address the NE in clinical trials, this may be unfeasible due the critical ethical component of failing to inform a patient clearly about the procedures, known risks, and consequences, as well as the fact that untreated patients suffer from a serious condition.

\section{EFFICACY OF ANTIDEPRESSANTS}

Currently, fluoxetine is the only antidepressant supported by the FDA for treatment of MDD in children aged 8 years and older. Also, our analysis indicates that fluoxetine has higher improvement on depression scales over placebo. However, the clinical status of fluoxetine use on pediatric patients remains in constant discussion due the incidence of suicidal ideation and suicidal attempts shown in previous clinical trials (Hetrick et al., 2012). In this order, the current recommendation is a constant monitoring of $\mathrm{AE}$ in patients taking SSRIs (Silva and Sampaio, 2011).

The efficacy analysis of antidepressants in depressive C\&A when compared with placebo shows a mild statistically significant reduction in the depression scales used to determine the effect of treatment, which stood out in the Emslie et al. (2002) RCT (active drug was fluoxetine) due its marked efficacy over placebo (mean difference of -7.10 with $95 \%$ CI -11.69 to -2.51 ). Furthermore, the subgroup analysis of pharmacologic drug efficacy of antidepressants indicated that only SSRIs did significantly better than placebo, compared with SNRIs and TCAs. In particular, the current study findings indicate that fluoxetine has higher improvement on depression scales over placebo, consistent with the general use of fluoxetine as the primary treatment choice for C\&A depression (Raz, 2006).

Regarding the treatment of the depressive population below 19 years old, there remains a discussion concerning the potential risk-benefit of SSRI treatment. Symptoms such as suicide ideation and suicide attempt may be considered as an inherent AE of these medications, a nocebo effect, or even due to the nature of the disease. Furthermore, Silva and Sampaio (2011) have proposed that these AE could be product of an underlying bipolar disorder in $\mathrm{C} \& \mathrm{~A}$ undergoing treatment for MDD. In this order, the current recommendation is a constant monitoring of $\mathrm{AE}$ in patients taking these SSRIs.

An important concern that arises due to the lack of a wellknown safe and effective treatment for C\&A with MDD is the high rate of off-label prescription of antidepressants in this population. Compared with patients aged between 19 and 24 years, Czaja and Valuck (2012) found that patients under 18 had a higher number of 
prescriptions without strong support from the FDA. Antidepressants in C\&A is less effective than the response obtained in adult patients, both in terms of treatment response and AE profile.

\section{Assessing the heterogeneity of the clinical trials}

The heterogeneity assessment showed homogeneous results for the pooled effect size of $\mathrm{AE}\left(I^{2}=0\right.$, Figure 3$)$. The explanation is that risks for AE were similar across the trials. In contrast, high heterogeneity was demonstrated in the efficacy analysis $\left(I^{2}=96 \%\right.$, Figure 4A). Heterogeneity for the efficacy analysis was related with the high variance of the pooled effect size in the improvement of depression scales: in TCA trials, placebo did better, while SSRIs did better than placebo.

We showed robustness of the results with the sensitivity analysis. After the exclusion of any trial from the analysis, the overall result did not modify significantly, neither of AE for efficacy analysis.

\section{LIMITATIONS}

Our study has several limitations: first, attempts to obtain missing data were unsuccessful. Second, there was an inconsistency on adverse events' assessment and report across the studies, with less than half of trials reporting the number of patients who presented $\mathrm{AE}$, and without information about severity and about a potential relation between the symptom and the treatment, which constituted a constraint to perform the quantitative analysis for adverse events. Moreover, studies do not specify the type of AE assessment method used according to the nature of the symptom presented and studies used multiple methods for AE assessment, likely leading to different results. For instance, the structured approach was the most frequent assessment method for AE in RCTs, using scales, checklists, and questionnaires that led to only look for a specific set of AE. Others used a combination of methods, including clinician observation and patient spontaneous report, which might lead to a biased overestimation or underestimation of $\mathrm{AE}$ and decrease the quality of the adverse events reported. Third, the high proportion of unclear and high risk of bias within and across studies is concerning. Lack of information regarding the randomization, blinding process, and few details about the allocation concealment sequence might increase the probability of foreseeing the allocation group of participants and skew the primary outcome of the included trials (Schulz and Grimes, 2002). Finally, there were high rates of dropouts and withdrawals leading to a high risk of attrition bias, but none of the included studies described completely the frequency and reasons of dropouts in each intervention group, which did not allow to perform a deep analysis of dropouts in those patients allocated to active or control arms.

\section{CONCLUSION}

The frequency of adverse effects did not differ between active treatment and placebo arms; moreover, the benefits of depressive treatment are mild and vary between studies. Our findings highlight the similar risk of presenting $\mathrm{AE}$ for patients receiving placebo compared to antidepressant treatment, indicative of (a) the relative safety of antidepressants and (b) possible NE.

\section{IMPLICATIONS FOR PRACTICE}

Analysis of antidepressants' efficacy for C\&A showed an improvement of depression scales in patients taking SSRIs. Although SSRIs are the first line of pharmacological treatment for depressive C\&A, there still remains a gap of knowledge regarding the safety profile due to suicidal-related attempts. For this reason, it is imperative to keep a constant monitoring of adverse events in patients undergoing SSRI treatment.

Our findings highlight the similar risk of presenting AE for patients receiving placebo compared to antidepressant treatment. It is of note that in clinical context, as well as in the research arena, there are some aspects to identify and address in depressive C\&A in order to decrease the NE. The influence of parents' expectations, anxiety-related symptoms of depression, and "therapeutic rituals" might influence the nocebo phenomenon.

\section{IMPLICATIONS FOR RESEARCH}

The influence of NE over the adverse events' profile of antidepressants still remains doubtful, and it may be necessary to conduct further studies that allow understanding of the nature of nocebo phenomenon, perhaps also with no-treatment arms. For future studies, it is necessary to implement standardized methods to assess and report AE in RCTs of antidepressants in C\&A.

It is imperative to clearly report methodological aspects of clinical trials in order to reduce the risk of bias related to randomization process, blinding of personnel and participants, allocation concealment method, and the report of dropouts and reasons for them. Strengthening these efforts should assure readers a complete understanding of the methodology and the quality of the results.

\section{AUTHOR CONTRIBUTIONS}

Dr. Rojas-Mirquez and Dr. Rodriguez-Zuñiga had full access to all of the data in the study and take responsibility for the integrity of the data and the accuracy of the data analysis, and also have contributed equally to the work. Study concept and design: Dr. Linnman, Dr. Borsook, Dr. Becerra, Dr. Rojas-Mirquez, Dr. Rodriguez, Dr. Bonilla-Escobar, and Dr. Garcia-Perdomo. Acquisition of data: Dr. Rojas and Dr. Rodriguez. Analysis and interpretation of data: Johanna Carolina Rojas-Mirquez, Research Fellow in Anesthesia at Harvard Medical School; Milton RodriguezZuñiga, Research Fellow in Anesthesia at Harvard Medical School; Francisco Bonilla-Escobar, Research Associate at Instituto Cisalva, School of Public Health, Cochrane Center at Universidad del Valle, Cali, Colombia; Herney Garcia-Perdomo, Researcher and Professor, Cochrane Center at Universidad del Valle, Cali, Colombia. Drafting of the manuscript: All authors. Critical revision of the manuscript for important intellectual content: Dr. Bonilla-Escobar, Dr. Garcia-Perdomo, Dr. Borsook, Dr. Linnman, Dr. Rojas-Mirquez, Dr. Rodriguez-Zuñiga, and Mr. Mike Petkov. Study supervision: Dr. Bonilla-Escobar, Dr. Garcia-Perdomo, Dr. Borsook, and Dr. Linnman.

\section{ACKNOWLEDGMENTS}

This study was supported by NCCAM R21 AT007530 (David Borsook and Clas Linnman). 


\section{SUPPLEMENTARY MATERIAL}

The Supplementary Material for this article can be found online at http://www.frontiersin.org/Journal/10.3389/fnbeh.2014.00375/ abstract

\section{REFERENCES}

Almeida-Montes, L. G. F. A. (2005). Treatment of major depressive disorder with fluoxetine in children and adolescents. A double-blind, Placebo-controlled study. Psiq Biol. 12, 198-205.

Amanzio, M. (2011). Do we need a new procedure for the assessment of adverse events in anti-migraine clinical trials? Recent Pat. CNS Drug Discov. 6, 41-47. doi:10.2174/157488911794079109

Amanzio, M., Corazzini, L. L., Vase, L., and Benedetti, F. (2009). A systematic review of adverse events in placebo groups of anti-migraine clinical trials. Pain 146, 261-269. doi:10.1016/j.pain.2009.07.010

Ashraf, B., Saaiq, M., and Zaman, K. U. (2014). Qualitative study of nocebo phenomenon (NP) involved in doctor-patient communication. Int. J. Health Policy Manag. 3, 23-27. doi:10.15171/ijhpm.2014.54

Bavbek, S., Aydin, O., Sozener, Z. C., and Yuksel, S. (2014). Determinants of nocebo effect during oral drug provocation tests. Allergol Immunopathol (Madr). doi:10.1016/j.aller.2014.04.008

Benedetti, F. (2012). Placebo-induced improvements: how therapeutic rituals affect the patient's brain. J. Acupunct. Meridian Stud. 5, 97-103. doi:10.1016/j.jams. 2012.03.001

Benedetti, F., and Amanzio, M. (2011). The placebo response: how words and rituals change the patient's brain. Patient Educ. Couns. 84, 413-419. doi:10.1016/j.pec. 2011.04.034

Benedetti, F., and Amanzio, M. (2013). Mechanisms of the placebo response. Pulm. Pharmacol. Ther. 26, 520-523. doi:10.1016/j.pupt.2013.01.006

Berard, R., Fong, R., Carpenter, D. J., Thomason, C., and Wilkinson, C. (2006). An international, multicenter, placebo-controlled trial of paroxetine in adolescents with major depressive disorder. J. Child Adolesc. Psychopharmacol. 16, 59-75. doi:10.1089/cap.2006.16.59

Bingel, U. (2014). Avoiding nocebo effects to optimize treatment outcome. JAMA 312, 693-694. doi:10.1001/jama.2014.8342

Bohman, H., Jonsson, U., Paaren, A., von Knorring, L., Olsson, G., and von Knorring, A. L. (2012). Prognostic significance of functional somatic symptoms in adolescence: a 15-year community-based follow-up study of adolescents with depression compared with healthy peers. BMC Psychiatry 12:90. doi:10.1186/1471-244X-12-90

Bollen, K. A., and Brand, J. E. A. (2010). General panel model with random and fixed effects: a structural equations approach. Soc. Forces 89, 1-34. doi:10.1353/ sof. 2010.0072

Brambilla, P., Cipriani, A., Hotopf, M., and Barbui, C. (2005). Side-effect profile of fluoxetine in comparison with other SSRIs, tricyclic and newer antidepressants: a meta-analysis of clinical trial data. Pharmacopsychiatry 38, 69-77. doi:10.1055/s-2005-837806

Bridge, J. A., Iyengar, S., Salary, C. B., Barbe, R. P., Birmaher, B., Pincus, H. A., et al. (2007). Clinical response and risk for reported suicidal ideation and suicide attempts in pediatric antidepressant treatment: a meta-analysis of randomized controlled trials. JAMA 297, 1683-1696. doi:10.1001/jama.297.15.1683

Casper, R. C., Tollefson, G. D., and Nilsson, M. E. (2001). No gender differences in placebo responses of patients with major depressive disorder. Biol. Psychiatry 49, 158-160. doi:10.1016/S0006-3223(00)00966-5

Ciaramella, A., Paroli, M., and Poli, P. (2013). An emerging dimension in psychosomatic research: the nocebo phenomenon in the management of chronic pain. ISRN Neurosci. 2013, 6. doi:10.1155/2013/574526

Cohen, S. (2014). The nocebo effect of informed consent. Bioethics 28, 147-54. doi:10.1111/j.1467-8519.2012.01983.x

Colloca, L., and Miller, F. G. (2011). The nocebo effect and its relevance for clinical practice. Psychosom. Med. 73, 598-603. doi:10.1097/PSY.0b013e3182294a50

Czaja, A. S., and Valuck, R. (2012). Off-label antidepressant use in children and adolescents compared with young adults: extent and level of evidence. Pharmacoepidemiol. Drug Saf. 21, 997-1004. doi:10.1002/pds.3312

Data-Franco, J., and Berk, M. (2013). The nocebo effect: a clinicians guide. Aust. N. Z. J. Psychiatry 47, 617-623. doi:10.1177/0004867412464717

Der-Simonian, R., and Laird, N. (1986). Meta-analysis in clinical trials. Control. Clin. Trials 7, 177-188. doi:10.1016/0197-2456(86)90046-2
Eli Lilly and Company. (2013a). A Study in the Treatment of Children and Adolescents With Major Depressive Disorder. Available at: http://www.clinicaltrials.gov/ ct2/show/NCT00849901

Eli Lilly and Company. (2013b). A Study in the Treatment of Children and Adolescents With Major Depressive Disorder. Available at: http://www.clinicaltrials.gov/ ct2/show/NCT00849693

Emslie, G. J., Heiligenstein, J. H., Wagner, K. D., Hoog, S. L., Ernest, D. E., Brown, E., et al. (2002). Fluoxetine for acute treatment of depression in children and adolescents: a placebo-controlled, randomized clinical trial. J. Am. Acad. Child Adolesc. Psychiatry 41, 1205-1215. doi:10.1097/00004583-200210000-00010

Emslie, G. J., Ventura, D., Korotzer, A., and Tourkodimitris, S. (2009). Escitalopram in the treatment of adolescent depression: a randomized placebocontrolled multisite trial. J. Am. Acad. Child Adolesc. Psychiatry 48, 721-729. doi:10.1097/CHI.0b013e3181a2b304

Emslie, G. J., Wagner, K. D., Kutcher, S., Krulewicz, S., Fong, R., Carpenter, D. J., et al. (2006). Paroxetine treatment in children and adolescents with major depressive disorder: a randomized, multicenter, double-blind, placebo-controlled trial. $J$. Am. Acad. Child Adolesc. Psychiatry 45, 709-719. doi:10.1097/01.chi.0000214189. 73240.63

Faasse, K., and Petrie, K. J. (2013). The nocebo effect: patient expectations and medication side effects. Postgrad. Med. J. 89, 540-546. doi:10.1136/postgradmedj2012-131730

Fernandes, R., Ferreira, J. J., and Sampaio, C. (2008). The placebo response in studies of acute migraine. J. Pediatr. 152, 527-533,533e521. doi:10.1016/j.jpeds. 2007.09.024

Geller, B., Cooper, T. B., Graham, D. L., Fetner, H. H., Marsteller, F. A., and Wells, J. M. (1992). Pharmacokinetically designed double-blind placebo-controlled study of nortriptyline in 6- to 12-year-olds with major depressive disorder. J. Am. Acad. Child Adolesc. Psychiatry 31, 34-44. doi:10.1097/00004583-19920100000007

Ghandour, R. M., Overpeck, M. D., Huang, Z. J., Kogan, M. D., and Scheidt, P. C. (2004). Headache, stomachache, backache, and morning fatigue among adolescent girls in the United States: associations with behavioral, sociodemographic, and environmental factors. Arch. Pediatr. Adolesc. Med. 158, 797-803. doi:10.1001/archpedi.158.8.797

GlaxoSmithKline. (2011). Paxil Japanese Post Marketing Paediatric Study in Depression (Double-blind, Placebo Controlled Study). Available at: http://www. clinicaltrials.gov/ct2/show/NCT00812812

Gracely, R. H., Dubner, R., Deeter, W. R., and Wolskee, P. J. (1985). Clinicians' expectations influence placebo analgesia. Lancet 1, 43. doi:10.1016/S0140-6736(85) 90984-5

Hauser, W., Hansen, E., and Enck, P. (2012a). Nocebo phenomena in medicine: their relevance in everyday clinical practice. Dtsch. Arztebl. Int. 109, 459-465. doi:10.3238/arztebl.2012.0459

Hauser, W., Bartram, C., Bartram-Wunn, E., and Tolle, T. (2012b). Adverse events attributable to nocebo in randomized controlled drug trials in fibromyalgia syndrome and painful diabetic peripheral neuropathy: systematic review. Clin. J. Pain 28, 437-451. doi:10.1097/AJP.0b013e3182321ad8

Hazell, P. (2009). Depression in children and adolescents. Clin. Evid. 12, 427-442.

Hazell, P., and Mirzaie, M. (2013). Tricyclic drugs for depression in children and adolescents. Cochrane Database Syst. Rev. 6:CD002317. doi:10.1002/14651858. CD002317.pub2

Hegerl, U., Hautzinger, M., Mergl, R., Kohnen, R., Schütze, M., Scheunemann, W., et al. (2010). Effects of pharmacotherapy and psychotherapy in depressed primary-care patients: a randomized, controlled trial including a patients' choice arm. Int. J. Neuropsychopharmacol. 13, 31-44. doi:10.1017/S1461145709000224

Hetrick, S. E., McKenzie, J. E., Cox, G. R., Simmons, M. B., and Merry, S. N. (2012) Newer generation antidepressants for depressive disorders in children and adolescents. Cochrane Database Syst. Rev. 11:CD004851. doi:10.1002/14651858. CD004851.pub3

Higgins, J. P., Altman, D. G., Gøtzsche, P. C., Jüni, P., Moher, D., Oxman, A. D., et al. (2011). The Cochrane collaboration's tool for assessing risk of bias in randomised trials. BMJ 343, d5928. doi:10.1136/bmj.d5928

Higgins, J. P., Thompson, S. G., Deeks, J. J., and Altman, D. G. (2003). Measuring inconsistency in meta-analyses. BMJ 327, 557-560. doi:10.1136/bmj. 327.7414.557

Higgins, J. P. T., and Green, S. (2011a). "Cochrane handbook for systematic reviews of intervention," in The Cochrane Collaboration. Available at: http: //www.cochrane-handbook.org 
Higgins, J. P. T., and Green, S. (2011b). “14.6.1 clinical trials,” in Cochrane Handbook for Systematic Reviews of Interventions Version 5.1.0, eds J. P. T. Higgins and S. Green (The Cochrane Collaboration). p. 442-443.

Jones, K. A., and Thomsen, C. (2013). The role of the innate immune system in psychiatric disorders. Mol. Cell. Neurosci. 53, 52-62. doi:10.1016/j.mcn.2012.10.002

Keller, M. B., Ryan, N. D., Strober, M., Klein, R. G., Kutcher, S. P., Birmaher, B., et al. (2001). Efficacy of paroxetine in the treatment of adolescent major depression: a randomized, controlled trial. J. Am. Acad. Child Adolesc. Psychiatry 40, 762-772. doi:10.1097/00004583-200107000-00010

Kutcher, S., Boulos, C., Ward, B., Marton, P., Simeon, J., Ferguson, H. B., et al. (1994). Response to desipramine treatment in adolescent depression: a fixeddose, placebo-controlled trial. J. Am. Acad. Child Adolesc. Psychiatry 33, 686-694. doi:10.1097/00004583-199406000-00010

Kye, C. H., Waterman, G. S., Ryan, N. D., Birmaher, B., Williamson, D. E., Iyengar, S., et al. (1996). A randomized, controlled trial of amitriptyline in the acute treatment of adolescent major depression. J. Am. Acad. Child Adolesc. Psychiatry 35, 1139-1144. doi:10.1097/00004583-199609000-00011

Mitsikostas, D. D., Chalarakis, N. G., Mantonakis, L. I., Delicha, E. M., and Sfikakis, P. P. (2012). Nocebo in fibromyalgia: meta-analysis of placebo-controlled clinical trials and implications for practice. Eur. J. Neurol. 19, 672-680. doi:10.1111/ j.1468-1331.2011.03528.x

Moher, D., Liberati, A., Tetzlaff, J., and Altman, D. G. (2009). Preferred reporting items for systematic reviews and meta-analyses: the PRISMA statement. J. Clin. Epidemiol. 62, 1006-1012. doi:10.1016/j.jclinepi.2009.06.005

Mora, M. S., Nestoriuc, Y., and Rief, W. (2011). Lessons learned from placebo groups in antidepressant trials. Philos. Trans. R. Soc. Lond. B Biol. Sci. 366, 1879-1888. doi:10.1098/rstb.2010.0394

Nardi, B., Francesconi, G., Catena-Dell'osso, M., and Bellantuono, C. (2013). Adolescent depression: clinical features and therapeutic strategies. Eur. Rev. Med. Pharmacol. Sci. 17, 1546-1551.

National Center for Biotechnology Information, and U.S. National Library of Medicine. (2013a). Medical Subject Headings, "Child". Available at: http://www.ncbi. nlm.nih.gov/mesh/68002648

National Center for Biotechnology Information, and U.S. National Library of Medicine. (2013b). Medical Subject Headings, "Adolescent". Available at: http: //www.ncbi.nlm.nih.gov/mesh/68000293

Raz, A. (2006). Perspectives on the efficacy of antidepressants for child and adolescent depression. PLoS Med. 3:e9. doi:10.1371/journal.pmed.0030009

Rief, W., Nestoriuc, Y., von Lilienfeld-Toal A., Dogan, I., Schreiber, F., Hofmann, S. G., et al. (2009). Differences in adverse effect reporting in placebo groups in SSRI and tricyclic antidepressant trials: a systematic review and meta-analysis. Drug Saf. 32, 1041-1056. doi:10.2165/11316580-000000000-00000

Rogers, M. P. (2003). Headaches and the nocebo effect. Headache 43, 1113-1115. doi:10.1046/j.1526-4610.2003.03216.x

Rojas-Mirquez, J. C., Rodriguez-Zuñiga, M. J. M., Borsook, D., Linnman, C., BonillaEscobar, F. J., and Garcia-Perdomo, H. A. (2013). Nocebo Effect in Randomized Clinical Trials of Antidepressants in Children and Adolescents: Systematic Review and Meta-Analysis. PROSPERO 2013: CRD42013004638 2013. Available at: http: //www.crd.york.ac.uk/PROSPERO/display_record.asp?ID=CRD42013004638

Schulz, K. F., and Grimes, D. A. (2002). Allocation concealment in randomised trials: defending against deciphering. Lancet 359, 614-618. doi:10.1016/S01406736(02)07750-4

Silva, M., and Sampaio, D. (2011). [Antidepressants and suicide in adolescents]. Acta Med. Port. 24, 603-612.
Simeon, J. G., Dinicola, V. F., Ferguson, H. B., and Copping, W. (1990). Adolescent depression: a placebo-controlled fluoxetine treatment study and follow-up. Prog. Neuropsychopharmacol. Biol. Psychiatry 14, 791-795. doi:10.1016/02785846(90)90050-Q

Sterne, J. A. C. E. M., and Moher, D. (2011). "Chapter 8: assessing risk of bias in included studies," in The Cochrane Collaboration, eds J. P. T. Higgins and S. Green. Available at: http://www.cochrane-handbook.org

Undurraga, J., and Baldessarini, R. J. (2012). Randomized, placebo-controlled trials of antidepressants for acute major depression: thirty-year meta-analytic review. Neuropsychopharmacology 37, 851-864. doi:10.1038/npp.2011.306

van Laarhoven, A. I., Vogelaar, M. L., Wilder-Smith, O. H., van Riel, P. L., van de Kerkhof, P. C., Kraaimaat, F. W., et al. (2011). Induction of nocebo and placebo effects on itch and pain by verbal suggestions. Pain 152, 1486-1494. doi:10.1016/j.pain.2011.01.043

Wagner, K. D., Ambrosini, P., Rynn, M., Wohlberg, C., Yang, R., Greenbaum, M. S., et al. (2003). Efficacy of sertraline in the treatment of children and adolescents with major depressive disorder: two randomized controlled trials. JAMA 290, 1033-1041. doi:10.1001/jama.290.8.1033

Wagner, K. D., Jonas, J., Findling, R. L., Ventura, D., and Saikali, K. (2006). A double-blind, randomized, placebo-controlled trial of escitalopram in the treatment of pediatric depression. J. Am. Acad. Child Adolesc. Psychiatry 45, 280-288. doi:10.1097/01.chi.0000192250.38400.9e

Wagner, K. D., Robb, A. S., Findling, R. L., Jin, J., Gutierrez, M. M., and Heydorn, W. E. (2004). A randomized, placebo-controlled trial of citalopram for the treatment of major depression in children and adolescents. Am. J. Psychiatry 161, 1079-1083. doi:10.1176/appi.ajp.161.6.1079

Wells, R. E., and Kaptchuk, T. J. (2012). To tell the truth, the whole truth, may do patients harm: the problem of the nocebo effect for informed consent. Am. J. Bioeth. 12, 22-29. doi:10.1080/15265161.2011.652798

Wendt, L., Albring, A., Benson, S., Engler, H., Engler, A., Hinney, A., et al. (2014). Catechol-O-methyltransferase Val158Met polymorphism is associated with somatosensory amplification and nocebo responses. PLoS ONE 9:e107665. doi:10.1371/journal.pone.0107665

Conflict of Interest Statement: The authors report no biomedical financial interests or potential conflicts of interest, neither have published nor submitted any related paper from this study.

Received: 12 June 2014; accepted: 10 October 2014; published online: 03 November 2014

Citation: Rojas-Mirquez JC, Rodriguez-Zuñiga MJM, Bonilla-Escobar FJ, GarciaPerdomo HA, Petkov M, Becerra L, Borsook D and Linnman C (2014) Nocebo effect in randomized clinical trials of antidepressants in children and adolescents: systematic review and meta-analysis. Front. Behav. Neurosci. 8:375. doi: 10.3389/fnbeh.2014.00375

This article was submitted to the journal Frontiers in Behavioral Neuroscience. Copyright (C) 2014 Rojas-Mirquez, Rodriguez-Zuñiga, Bonilla-Escobar, GarciaPerdomo, Petkov, Becerra, Borsook and Linnman. This is an open-access article distributed under the terms of the Creative Commons Attribution License (CC BY). The use, distribution or reproduction in other forums is permitted, provided the original author(s) orlicensor are credited and that the original publication in this journal is cited, in accordance with accepted academic practice. No use, distribution or reproduction is permitted which does not comply with these terms. 